\title{
Treatment of psychosis in prisons and violent recidivism
}

\author{
Artemis Igoumenou, Constantinos Kallis and Jeremy Coid
}

\section{Background}

Violence among released prisoners with psychosis is an important public health problem. It is unclear whether treatment in prison can influence criminal behaviour subsequent to release.

\section{Aims}

To investigate whether treatment in prison can delay time to reoffending.

\section{Method}

Our sample consisted of 1717 adult prisoners in England and Wales convicted of a serious violent or sexual offence. We used cox regression to investigate the effects of treatment received in prison on associations between mental illness and time to first reconviction following release.

\section{Results}

Prisoners with current symptoms of schizophrenia reoffended quicker following release. Nevertheless, treatment with medication significantly delayed time to violence (18\% reduction). Treatment for substance dependence delayed violent and non-violent reoffending among prisoners with drug-induced psychosis.

\section{Conclusions}

Identifying prisoners with psychosis and administering treatment in prison have important protective effects against reoffending. Repeated screening with improved accuracy in identification is necessary to prevent cases being missed.

\section{Declaration of interest}

None.

\section{Copyright and usage}

(c) The Royal College of Psychiatrists 2015. This is an open access article distributed under the terms of the Creative Commons Non-Commercial, No Derivatives (CC BY-NC-ND) licence.
Violent behaviour among released prisoners with severe mental illness is a significant public health problem. ${ }^{1}$ A systematic review reported high rates of mental illness in the prison population worldwide, with $3.6 \%$ of male and $3.9 \%$ of female prisoners having a diagnosis of psychosis, ${ }^{2}$ although a national survey which sampled from all penal establishments in England and Wales showed much higher prevalences. ${ }^{3}$ The relationship between severe mental disorder and reoffending in prisoners is complex. Prisoners with psychosis contrast with other prisoners without psychosis in having more comorbid psychopathology (anxiety, antisocial personality disorder), early behavioural problems and risk factors for future offending, including younger age, poor impulse control, hostile behaviour, lack of insight, non-adherence to psychological therapies or medication, recent substance misuse, higher general symptom as well as positive and negative symptom scores. ${ }^{4,5}$ Some studies report that released prisoners with mental disorders, particularly psychosis and bipolar disorder, are at increased risk of further imprisonment compared with those without a psychiatric diagnosis. ${ }^{6,7}$ However, others suggest that criminological risk factors are more important predictors of violent recidivism than clinical ones, ${ }^{8-10}$ that mood and psychotic symptoms are not directly related to the risk of recidivism, and increase risk of violence through comorbidity with personality disorders and substance dependence. ${ }^{11-13}$ It is unclear why findings are inconsistent. However, it has been suggested that the link between mental illness and violence will only emerge when temporal proximity of symptoms and violence are taken into account. ${ }^{1,14-16}$ In line with this hypothesis, recent studies of community and clinical samples, which consider symptoms occurring at the same time as the outcome, have demonstrated associations between severe mental illness and violence independent of personality disorder and substance misuse. ${ }^{14,16-18}$ However, few studies have considered the effects of treatment interventions on criminality. ${ }^{19}$ Not being in receipt of treatment while in prison and fol-lowing release is associated with increased risk of violence. ${ }^{1,5,20-22}$ A substantial number of released prisoners with psychosis do not receive treatment after release. ${ }^{22-24}$ Treatment while in custody may therefore be a unique opportunity for intervention and have an important role in public protection. However, because prisoners with psychosis demonstrate complex psychopathology with multiple comorbid conditions, it is unclear which treatments should be prioritised to prevent violence.

In the current study we aimed to investigate the relationship between mental illness and time to reoffending (first reconviction) among released prisoners with a diagnosis of psychosis. We examined violent and non-violent reoffending separately. Considering the role of the temporal proximity of symptoms, we investigated the effects of both a current and previous diagnosis of mental illness on recidivism. The UK Prisoner Cohort Study is an observational, longitudinal investigation of risk factors for future violence among prisoners convicted of a serious violent or sexual offence. We aimed to investigate: (a) whether released prisoners with mental illness reoffend quicker than their non-mentally ill counterparts; (b) whether treatments for mental disorders in prison delay reoffending; and (c) whether comorbidity with substance addiction or personality disorders explain the relationship between mental illness and time to reoffending.

\section{Method}

\section{Sample}

The study design and sample characteristics have previously been described in detail. ${ }^{25}$ In summary, the Prisoner Cohort Study was a large longitudinal study designed to identify predictors of reoffending among prisoners released into the community from prisons in England and Wales. It was commissioned in 2001 by the UK Ministry of Justice (formerly the Home Office). Participants were male and female adult offenders serving sentences of $2+$ years for a sexual or violent index offence who were expected to be released within 12 months (life sentence prisoners were excluded). They were identified from the Prison Service 
Inmate Information System. Written informed consent was obtained from all participants.

For the purposes of the Prisoner Cohort Study, the Offenders Group Reconviction Scale (OGRS) was used to sample participants from a range of scores, with those of highest risk over sampled. OGRS has been found to be an accurate predictor of recidivism and is calculated considering the persons age and static risk factors. ${ }^{25,26}$ A stratified sample of 3143 male and 391 female prisoners was identified. ${ }^{25,26}$ Among the selected sample, 663 males $(21.1 \%)$ and $35(9.0 \%)$ females refused to participate, and 1081 males (34.4\%) and 35 (9.0\%) females could not be interviewed (unsuitable, died, deported prior to recruitment). The study sample consisted of 1717 participants: 1396 male and 321 female prisoners. Reoffending was measured following release into the community over a median follow-up of 6.22 years (range $0.83-7.26)$.

\section{Measures}

Participants had a semi-structured interview in prison which collected data on clinical and risk-assessment measures for criminal behaviour.

Both current and lifetime (previous but not current) diagnoses of schizophrenia, delusional disorder and depression were established using a module from the Schizophrenia and Affective Disorders Schedule - Lifetime version (SADS-L). ${ }^{27}$ Diagnosis of schizoaffective disorder $(n=26,1.5 \%)$ was included under the diagnostic category of 'schizophrenia' for statistical analysis, as clinically and diagnostically the two disorders overlap and because at different times during the course of schizoaffective disorder differences from schizophrenia may not always be apparent. ${ }^{28}$ However, we performed sensitivity analysis to investigate whether considering schizoaffective disorder separately altered our findings. We similarly considered delusional disorder separately from schizophrenia. Delusional disorder is a distinct clinical diagnosis and previous research has shown that individuals with the condition reoffend quicker following discharge from psychiatric services compared with those with schizophrenia. ${ }^{29}$ We therefore performed sensitivity analysis to investigate whether combining all psychotic disorders affected our results.

Inclusion of a diagnosis of drug-induced psychosis is more controversial. Contemporary researchers consider schizophrenia predominantly as a syndrome rather than a specific disease. ${ }^{30}$ In our sample, it was important to separate drug-induced psychosis from schizophrenia because of the large numbers of prisoners with this diagnosis. Furthermore, identifying potential triggers for the onset of a drug-induced psychosis has major implications for management and prognosis.

Alcohol dependence was established using the Alcohol Use Disorders Identification Test (AUDIT). ${ }^{31}$ Diagnoses of druginduced psychosis and drug dependence were established using DSM-IV criteria. Drug dependence was diagnosed using questions covering compulsive, out-of-control drug use and subjective feeling of dependence, unsuccessful attempts to quit, tolerance and withdrawal symptoms. Personality disorder was assessed using the Structured Clinical Interview for DSM-IV Axis II Personality Disorders (SCID-II). ${ }^{32}$ Interviews were conducted by research assistants trained in the use of these instruments after achieving satisfactory interrater reliability. ${ }^{25}$

Information on self-reported psychiatric treatment received during the current sentence was also collected. Treatments included consultations with a mental health professional, prescribed medication for a mental health problem and treatment for substance dependence, including treatment with medication and rehabilitation. Participants were asked whether they were prescribed medication at the time of the interview, whether the medication was for mental health or emotional problems and whether they received psychiatric/psychological treatment while in prison. They were also asked whether during their current sentence they had received drug or alcohol detoxification and rehabilitation. Details of prescribed psychotropic medication (name, preparation, dosage) and type of psychiatric and psychological treatment were not available. Similarly, information on continuity of treatment post-release was not available over the entire follow-up period.

Data on convictions were obtained from the Police National Computer (PNC) and included offences classified according to the UK Home Office's Standard List of Offences. Because we hypothesised that the associated risk factors (criminological, demographic, psychopathology) would differ, we separated violent from non-violent reoffending. Considering violent and nonviolent offending together would have improved the power of our study, however to the expense of the specificity of the results. Violent offending, according to the UK Home Office's Standard list of Violence against the Person, included offences such as homicide, violence with injury and violence without injury. The remaining offences were classified as non-violent offending.

\section{Statistical analysis}

We first investigated associations between psychosis and time to reoffending following release from prison. We separated previous from current diagnosis. We therefore had seven mutually exclusive categories: (a) no psychosis, (b) previous schizophrenia (no current symptoms), (c) current schizophrenia, (d) previous delusional disorder, (e) current delusional disorder, (f) previous drug-induced psychosis and (g) current drug-induced psychosis. We used univariate Cox regression to explore relationships between time to first reconviction and psychiatric morbidity. We considered violent and non-violent reoffending separately. We calculated time at risk (in days) as the time spent outside prison. Hence, for violent reoffending, time at risk was the time between release and reconviction for violence, minus time spent in prison. For non-violent reoffending, time at risk was the time between release and reconviction for a non-violent offence, minus time spent in prison.

Demographic characteristics (age, gender, ethnicity, marital status and socioeconomic status), demonstrated in the literature to be variables that can influence recidivism, were included as covariates in all adjusted models. ${ }^{1,33-36}$ Because gender can be an important source of heterogeneity with regard to both offending and psychopathology, we performed subgroup analysis. This did not change our results. We therefore included gender only as a covariate. Likewise we adjusted for comorbid depression. We also considered non-violent reoffending (binary outcome) as a covariate for 'time at risk' for violent offending. We similarly considered violent reoffending (binary outcome) as a covariate for 'time at risk' for non-violent offending. These variables were included as covariates in all adjusted models.

We next aimed to identify variables that could explain associations between mental illness and time to violence (and, in a separate analysis, non-violence) following release from prison. We therefore investigated whether associations between different diagnostic categories and time to reoffending were explained by treatments received in prison, specifically medication for mental illness, consultation with a mental health professional and treatment for substance dependence. Treatments for substance dependence were also considered as they were relevant in the case of drug-induced psychosis and consisted of treatments with medication or rehabilitation. Similarly, we investigated whether associations between different diagnostic categories and time to reoffending were explained by other diagnoses such as alcohol and 
drug dependence or personality disorder. All treatment and diagnostic (substance addiction and personality disorder) variables were binary. Potential explanatory variables were first identified by testing their association with (a) current and previous diagnoses of psychosis (schizophrenia, delusional disorder and drug-induced psychosis) and (b) time to reoffending (separate for violence and non-violence) following release from prison. Only if both associations were significant at $P<0.05$ were variables selected and subsequently entered in an adjusted model following a stepwise approach, with all mental illness categories as the independent variables and time to reoffending as the dependent variable.

We also used the \% change in the beta coefficient (beta=log (hazard ratio, HR)) to quantify the change in the effect of the exposure variables (psychosis) on the outcome (time to reoffending) that could be attributed to the explanatory variable, i.e. the relevant treatment, or other diagnosis. We used the formula:

Beta coefficient baseline - Beta coefficient adjusted Beta coefficient baseline

We used STATA version 13 in all our analyses. An alpha level of 0.05 was adopted throughout.

Following our main analysis, we finally performed sensitivity analysis to investigate whether re-categorisation of psychosis could have affected our results. We first repeated the above described analysis separating schizoaffective disorder from schizophrenia (hence we had eight categories for psychotic illness). We then repeated the analysis combining schizophrenia, schizoaffective disorder and delusional disorder.

\section{Results}

\section{Sample descriptive statistics}

Prisoners in our sample were mainly men $(n=1396,81.3 \%)$ with a mean age of 30.4 years (median $=27$, s.d. $=11.0$, range $18-75)$. The majority were White $(n=1364,79.4 \%)$, single $(n=932,54.3 \%)$ and of lower socioeconomic status $(n=1650,96.3 \%)$. In total, $49(2.9 \%)$ prisoners fulfilled the diagnostic criteria for previous and 116 (6.8\%) for current schizophrenia, 21 (1.2\%) for previous and 29 (1.7\%) for current delusional disorder, 153 (8.9\%) for previous and 50 (2.9\%) for current drug-induced psychosis, 503 (29.5\%) for previous and 125 (7.3\%) for current depression. Overall, 1482 $(87.4 \%)$ participants reoffended within 6 years of release, with 970 (57.2\%) convicted of at least one violent offence and 1450 (85.5\%) of at least one non-violent offence (prevalences of offences in Table 1). The median follow-up period was 6.22 years (range $0.83-7.26$ ). The median period at risk for violent offending was 5.1 years (range 0.01-7.26) and the median period at risk for nonviolent offending was 2.5 years (range $0.003-7.26$ ).

The risk of violent reoffending was reduced among women (odds ratio $(\mathrm{OR})=0.33,95 \%$ CI $0.24-0.46, P<0.001$ ), in older prisoners (OR $=0.94,95 \%$ CI $0.93-0.95, P<0.001)$, among those from the Asian subcontinent $(\mathrm{OR}=0.16,95 \%$ CI $0.05-0.53$, $P=0.003)$ and those of higher socioeconomic status $(\mathrm{OR}=0.10$, 95\% CI $0.03-0.33, P<0.001)$. It was increased among prisoners who were single $(\mathrm{OR}=1.73,95 \% \mathrm{CI} 1.40-2.13, P<0.001)$.

Similarly, the risk of non-violent reoffending was reduced among women $(\mathrm{OR}=0.42,95 \%$ CI $0.33-0.53, P<0.001)$, older prisoners $(\mathrm{OR}=0.93,95 \%$ CI $0.92-0.94, P<0.001)$ and those of higher socioeconomic status $(\mathrm{OR}=0.24, \quad 95 \%$ CI $0.14-0.42$, $P<0.001)$. It was increased among prisoners who were single $(\mathrm{OR}=2.04,95 \% \mathrm{CI} 1.68-2.49, P<0.001)$ and Black $(\mathrm{OR}=1.73,95 \%$ CI 1.28-2.34, $P<0.001)$.

$\begin{array}{lc}\text { Table } 1 \text { Prevalence of offences resulting in conviction after } \\ \text { release from prison } \\ \text { Offence category and type } \\ \text { Violent } \\ \text { Homicide } \\ \text { Major violence }{ }^{\text {a }} \\ \text { Minor violence } \\ \text { Non-violent } & 9(0.5) \\ \text { Possession of weapons/explosives } & 83(4.9) \\ \text { Possession of firearms } & 420(24.8) \\ \text { Kidnapping/abduction } & \\ \text { False imprisonment } & 158(9.3) \\ \text { Robbery } & 39(2.3) \\ \text { Aggravated burglary } & 5(0.3) \\ \text { Burglary } & 5(0.3) \\ \text { Theft/receiving stolen goods } & 156(9.2) \\ \text { Forgery } & 6(0.4) \\ \text { Rape/buggery } & 250(14.8) \\ \text { Indecent assault } & 551(32.5) \\ \text { Other sexual } & 105(6.2) \\ \text { Arson } & 4(0.4) \\ \text { Criminal damage } & 5(0.3) \\ \text { Drug-related offences } & 37(2.2) \\ \text { Alcohol-related convictions } & 8(0.5) \\ \text { Public order/harassment } & 230(13.6) \\ \text { Driving-related } & 357(21.1) \\ \text { Breaching release conditions } & 84(4.9) \\ \text { Obstructing justice } & 266(15.7) \\ \text { Escaping custody } & 380(22.4) \\ \text { a. Major violence includes life-threatening violence (but not homicide): attempted } \\ \text { b. Minor violence includes non-life threatening violence: assault, affray, offensive } \\ \text { weapon and threats. } \\ \end{array}$

Table 2 shows the prevalence of prisoners with psychosis reporting treatment during imprisonment. Most prisoners with a current diagnosis of schizophrenia reported receiving treatment with medication, but only half with current delusional disorder and a third with drug-induced psychosis received treatment with medication. The same trend was observed when consultations with a mental health professional were considered. Approximately $20.0 \%$ with previous or current schizophrenia received treatments for drug dependence. For drug-induced psychosis, a third with previous and a quarter with a current diagnosis reported receiving treatment for drug dependence.

Our findings indicate that 239 (18.5\%) of individuals without psychosis reported receiving psychotropic medications, and 361 (27.9\%) consulted a mental health professional. Similarly, 60 (4.6\%) prisoners without psychosis received treatment for alcohol dependence and 192 (14.8\%) for drug dependence. We found that 166 (19.6\%) prisoners without psychosis were taking psychotropic medications for treatment of their personality disorder, 260 (30.6\%) were consulting a mental health professional for personality disorder, and $40(4.7 \%)$ prisoners with personality disorder received treatment for alcohol dependence and 140 (16.5\%) for drug dependence.

Table 3 shows associations between reported treatments in prison and diagnosis of mental disorder, using separate logistic regression models. Prisoners with a previous or current diagnosis of schizophrenia were more likely to receive treatment for their mental illness (medication, consultation with a mental health professional) than prisoners without psychosis. Those with previous schizophrenia were also more likely to receive treatment for alcohol dependence compared with counterparts without psychosis. Prisoners with a previous diagnosis of drug-induced psychosis 
Table 2 Prevalence of prisoners with psychotic illness reporting treatment in prison

\begin{tabular}{|c|c|c|c|c|c|}
\hline \multirow[b]{3}{*}{ Psychosis } & \multirow[b]{3}{*}{$n(\%)$} & \multirow[t]{2}{*}{$\begin{array}{l}\text { Treatment with medication } \\
\text { during imprisonment }\end{array}$} & \multirow[t]{2}{*}{$\begin{array}{l}\text { Consultations with mental } \\
\text { health professional during } \\
\text { imprisonment }\end{array}$} & \multicolumn{2}{|c|}{$\begin{array}{l}\text { Treatments for drug and/or } \\
\text { alcohol dependence during } \\
\text { imprisonment }\end{array}$} \\
\hline & & & & Drug & Alcohol \\
\hline & & & $n(\%)$ & & \\
\hline Previous schizophrenia & $49(2.9)$ & $24(49.0)$ & $27(55.1)$ & $10(20.4)$ & 7 (14.3) \\
\hline Current schizophrenia & $116(6.8)$ & $81(69.8)$ & $85(73.3)$ & $23(19.8)$ & $12(10.3)$ \\
\hline Previous delusional disorder & $21(1.2)$ & $5(23.8)$ & $14(66.7)$ & $6(28.6)$ & $2(9.5)$ \\
\hline Current delusional disorder & $29(1.7)$ & $15(53.6)$ & $15(53.6)$ & $5(17.9)$ & $1(3.5)$ \\
\hline Previous drug-induced psychosis & $153(8.9)$ & $40(26.1)$ & $48(31.4)$ & $55(36.0)$ & $21(13.7)$ \\
\hline Current drug-induced psychosis & $50(2.9)$ & $17(34.0)$ & $18(36.0)$ & $13(26.0)$ & $7(14.0)$ \\
\hline
\end{tabular}

\begin{tabular}{|c|c|c|c|c|c|}
\hline & \multirow[b]{2}{*}{$n(\%)$} & $\begin{array}{l}\text { Treatment with } \\
\text { medication }\end{array}$ & $\begin{array}{l}\text { Consultation with } \\
\text { mental health } \\
\text { professional }\end{array}$ & $\begin{array}{c}\text { Alcohol dependence } \\
\text { treatment }\end{array}$ & $\begin{array}{l}\text { Drug dependence } \\
\text { treatment }\end{array}$ \\
\hline & & \multicolumn{4}{|c|}{ Odds ratio $(95 \% \mathrm{Cl})$} \\
\hline \multicolumn{2}{|l|}{ No psychosis } & ref & ref & ref & ref \\
\hline Previous schizophrenia & $49(2.9)$ & $3.75(1.98-7.13)^{* * * *}$ & $2.71(1.49-4.92)^{* * * *}$ & $2.89(1.21-6.86)^{*}$ & $-^{\mathrm{a}}$ \\
\hline Current schizophrenia & $116(6.8)$ & $6.64(4.12-10.70)^{* * * *}$ & $4.94(3.17-7.73)^{* * * *}$ & - & - \\
\hline Previous delusional disorder & $21(1.2)$ & - & $4.01(1.53-10.35)^{* * *}$ & $\begin{array}{cc}- \\
\end{array}$ & $\begin{array}{c}- \\
\end{array}$ \\
\hline Current delusional disorder & $29(1.7)$ & $4.23(1.83-9.81)^{* * *}$ & $2.49(1.16-5.43)^{*}$ & - & - \\
\hline Previous drug-induced psychosis & $153(8.9)$ & $1.83(1.20-2.79)^{* *}$ & - & $3.35(1.94-5.78)^{* * *}$ & $3.34(2.29-4.87)^{* * * *}$ \\
\hline Current drug-induced psychosis & $50(2.9)$ & - & - & $2.58(1.08-6.15)^{*}$ & - \\
\hline \multicolumn{6}{|c|}{$\begin{array}{l}\text { Ref, reference category. } \\
{ }^{*} P<0.05 ;{ }^{* *} P<0.01 ; * * * P<0.001 \text {. } \\
\text { a. Not statistically significant results. Method: logistic regression. Adjusted for age (in years), gender, marital status, ethnicity and socioeconomic status. Also adjusted for comorbid } \\
\text { depression. }\end{array}$} \\
\hline
\end{tabular}

were more likely to receive treatment with medication for mental illness and treatments for substance dependence compared with prisoners without psychosis. Those with current drug-induced psychosis were more likely to receive treatment for alcohol dependence than inmates without psychosis.

\section{Psychopathology and time to violent reoffending}

We investigated associations between psychosis and time to violent reoffending following release from prison, adjusted for demographic characteristics (age, gender, ethnicity, marital status and social class), comorbid depression and non-violent offending. Tables 4 and 5 (column referring to baseline model; effects of psychiatric diagnosis adjusted for demography) show that only a current diagnosis of schizophrenia and previous and current diagnoses of drug-induced psychosis were significantly associated with shorter time to subsequent violent offending. No other diagnostic category was associated with time to violent reoffending following release from prison.

Comorbid diagnoses of alcohol $(\mathrm{HR}=1.51,95 \%$ CI $1.25-1.82$, $P<0.001)$ and drug dependence $(\mathrm{HR}=1.64,95 \%$ CI $1.38-1.95$, $P<0.001)$, antisocial $(\mathrm{HR}=2.63,95 \%$ CI $2.10-3.29, \quad P<0.001)$ and borderline personality disorder $(\mathrm{HR}=1.36,95 \%$ CI $0.08-0.14$, $P=0.003$ ) were associated with shorter time to violent reoffending following release.

\section{Treated and untreated mental illness and time to violent reoffending}

Table 6 shows associations between treatment received in prison and time to reoffending following release. Only treatments with medication for mental illness and for substance dependence were associated with time to violent reoffending, and therefore included in subsequent analyses. Consultation with a mental health

\begin{tabular}{|c|c|c|c|c|c|c|c|c|c|c|c|c|}
\hline & \multirow[b]{2}{*}{$n(\%)$} & \multicolumn{3}{|c|}{$\begin{array}{l}\text { Baseline model: adjusted } \\
\text { for demography }\end{array}$} & \multicolumn{4}{|c|}{$\begin{array}{l}\text { Further adjustment for treatment } \\
\text { with medication }\end{array}$} & \multicolumn{4}{|c|}{$\begin{array}{l}\text { Further adjustments for } \\
\text { treatments for drug and alcohol } \\
\text { dependence }\end{array}$} \\
\hline & & HR & $95 \% \mathrm{Cl}$ & $P$ & $\mathrm{HR}$ & $95 \% \mathrm{Cl}$ & $P$ & $\%^{\mathrm{b}}$ & HR & $95 \% \mathrm{Cl}$ & $P$ & $\%^{\mathrm{b}}$ \\
\hline Previous schizophrenia & $49(2.9)$ & 1.23 & $0.71-2.16$ & 0.460 & - & & & & - & - & - & - \\
\hline Current schizophrenia & $116(6.8)$ & 1.67 & $1.20-2.34$ & 0.003 & 1.53 & $1.08-2.16$ & 0.017 & 18 & - & - & - & - \\
\hline Previous delusional disorder & $21(1.2)$ & 1.76 & $0.72-4.29$ & 0.217 & - & - & - & - & & - & - & - \\
\hline Current delusional disorder & $29(1.7)$ & 0.99 & $0.53-1.85$ & 0.969 & - & - & - & - & & - & - & - \\
\hline Previous drug-induced psychosis & $153(8.9)$ & 1.58 & $1.21-2.06$ & 0.001 & 1.55 & $1.19-2.02$ & 0.001 & 4 & 1.39 & $1.06-1.82$ & 0.018 & 29 \\
\hline Current drug-induced psychosis & $50(2.9)$ & 1.54 & $1.00-2.36$ & 0.049 & 1.54 & $1.00-2.36$ & 0.050 & 0.2 & - & - & - & - \\
\hline \multicolumn{13}{|c|}{$\begin{array}{l}\text { a. Method: Cox regression. Adjusted for age (in years), gender, marital status, ethnicity and socioeconomic status. Also adjusted for comorbid depression. Further adjustment for } \\
\text { non-violent offending. } \\
\text { b. Percentage change in beta coefficient (beta=log (hazard ratio, HR) from baseline model to final adjusted model. Reported results when \% change in beta coefficient increased } \\
\text { compared with previous step. } \\
\text { Values in bold are significant. }\end{array}$} \\
\hline
\end{tabular}


Table 5 Associations of psychotic illness with time to violent reoffending

\begin{tabular}{|c|c|c|c|c|c|c|c|c|c|c|c|}
\hline & \multicolumn{3}{|c|}{$\begin{array}{l}\text { Baseline model: adjusted } \\
\text { for demography }{ }^{a}\end{array}$} & \multicolumn{4}{|c|}{$\begin{array}{c}\text { Further adjustment for treatment with } \\
\text { medication, treatments for drug and alcohol } \\
\text { dependence and diagnosis of alcohol } \\
\text { dependence }\end{array}$} & \multicolumn{4}{|c|}{$\begin{array}{l}\text { Further adjustments for diagnosis } \\
\text { of drug dependence }\end{array}$} \\
\hline & $\mathrm{HR}$ & $95 \% \mathrm{Cl}$ & $P$ & $\mathrm{HR}$ & $95 \% \mathrm{Cl}$ & $P$ & $\%^{b}$ & $\mathrm{HR}$ & $95 \% \mathrm{Cl}$ & $P$ & $\%^{\mathrm{b}}$ \\
\hline Previous schizophrenia & 1.23 & $0.71-2.16$ & 0.460 & - & & & & - & - & - & - \\
\hline Current schizophrenia & 1.67 & $1.20-2.34$ & 0.003 & 1.47 & $1.04-2.08$ & 0.028 & 25 & 1.39 & $0.98-1.97$ & 0.063 & 36 \\
\hline Previous delusional disorder & 1.76 & $0.72-4.29$ & 0.217 & - & - & - & - & & - & - & - \\
\hline Current delusional disorder & 0.99 & $0.53-1.85$ & 0.969 & - & - & - & - & & - & - & - \\
\hline Previous drug-induced psychosis & 1.58 & $1.21-2.06$ & 0.001 & 1.37 & $1.04-1.79$ & 0.024 & 32 & 1.24 & $0.94-1.63$ & 0.133 & 54 \\
\hline Current drug-induced psychosis & 1.54 & $1.00-2.36$ & 0.049 & - & - & - & - & - & - & - & - \\
\hline
\end{tabular}

\begin{tabular}{|c|c|c|c|c|}
\hline & $\begin{array}{l}\text { Treatment with } \\
\text { medication }\end{array}$ & $\begin{array}{c}\text { Consultation with mental health } \\
\text { professional }\end{array}$ & $\begin{array}{l}\text { Alcohol dependence } \\
\text { treatment }\end{array}$ & $\begin{array}{l}\text { Drug dependence } \\
\text { treatment }\end{array}$ \\
\hline & \multicolumn{4}{|c|}{ Hazard ratio $(95 \% \mathrm{Cl})$} \\
\hline Time to violence ${ }^{\mathrm{b}}$ & $1.33(1.07-1.65)^{*}$ & $1.17(0.97-1.41)$ & $1.72(1.29-2.31)^{\text {***** }}$ & $1.77(1.44-2.18)^{\text {**** }}$ \\
\hline Time to non-violence ${ }^{c}$ & $1.07(0.92-1.24)$ & $0.98(0.86-1.11)$ & $1.40(1.10-1.76)^{* * *}$ & $1.83(1.58-2.13)^{\text {**** }}$ \\
\hline
\end{tabular}

professional and time to violent recidivism following release did not reach statistical significance.

We next investigated effects of different treatments and coexisting diagnoses of alcohol or drug dependence on the relationship between mental illness and time to violence using a stepwise approach. The results are shown in the last two columns of Table 4 (for effects of treatments) and Table 5 (for effects of diagnosis of alcohol and drug dependence). We also used the \% change in the beta coefficient (beta $=\log (\mathrm{OR})$ ) to quantify change in the effect of the exposure variable (mental illness) on the outcome (time to violence) that could be attributed to the explanatory variable, i.e. the relevant treatment or comorbid diagnosis. The columns referring to the effects of psychosis on time to violence (adjusting for demography, depression and treatment with medication as well as adjusting for demography, depression treatment with medication and treatments for drug and alcohol dependence) demonstrate associations of mental illness with time to violent reoffending. They also present change in hazards ratio of mental illness and time to violence among prisoners, after adjusting for treatment for mental illness and substance dependence (percentage of change in odds (beta coefficient) explained by different treatments).

Following treatment with medication, the association between current schizophrenia and time to violent reoffending was moderately reduced in size and remained significant. The association between previous drug-induced psychosis and time to violent reoffending was not altered following adjustment for treatment with medication for the mental illness. However, following adjustment for treatment for substance dependence, the association between past drug-induced psychosis and time to violent reoffending was significantly reduced in size (29.0\%) but remained significant. Conversely, following adjustment for drug dependence, associations between current schizophrenia and time to violent reoffending, as well as between previous drug-induced psychosis and time to violent reoffending, no longer remained significant.

\section{Psychopathology and time to non-violent reoffending}

We investigated associations between psychiatric diagnosis and time to non-violent reoffending following release from prison, adjusted for demographic characteristics (age, gender, ethnicity, marital status and social class), comorbid depression and violent offending. Table 7 (column referring to baseline model; effects of psychiatric diagnosis adjusted for demography) shows that current diagnosis of schizophrenia and diagnoses of drug-induced psychosis (previous and current) were significantly associated with time to subsequent non-violent offending.

Comorbid diagnoses of drug dependence ( $\mathrm{HR}=1.79,95 \% \mathrm{CI}$ $1.58-2.03, P<0.001)$ and antisocial personality disorder $(\mathrm{HR}=1.82$, 95\% CI 1.56-2.11, $P<0.001)$ were associated with shorter time to non-violent reoffending following release. Obsessive-compulsive personality disorder ( $\mathrm{HR}=0.70,95 \%$ CI $0.53-0.92, P=0.009)$ was associated with longer time to non-violent reoffending following release.

\section{Treated and untreated mental illness and time to non-violent reoffending}

Treatment received in prison for alcohol (HR=1.40, 95\% CI 1.10$1.76, P=0.005)$ and drug dependence ( $\mathrm{HR}=1.83,95 \% \mathrm{CI} 1.58-2.13$, $P<0.001)$ were associated with time to non-violent reoffending following release, and therefore included in subsequent statistical analyses.

We investigated effects of treatment for alcohol and drug dependence and of coexisting diagnosis of drug dependence and personality disorder on the relationship between mental illness and time to non-violent offending using a stepwise approach. The results are shown in the last two columns of Table 7. After considering a diagnosis of drug dependence, the association 
Table 7 Associations of psychotic illness with time to non-violent reoffending

\begin{tabular}{|c|c|c|c|c|c|c|c|c|c|c|c|c|}
\hline & \multirow[b]{2}{*}{$n(\%)$} & \multicolumn{3}{|c|}{$\begin{array}{l}\text { Baseline model: adjusted } \\
\text { for demography }{ }^{a}\end{array}$} & \multicolumn{4}{|c|}{$\begin{array}{l}\text { Further adjustments for treatments for } \\
\text { alcohol and drug dependence }\end{array}$} & \multicolumn{4}{|c|}{$\begin{array}{l}\text { Further adjustments for drug } \\
\text { dependence diagnosis }\end{array}$} \\
\hline & & $H R$ & $95 \% \mathrm{Cl}$ & $P$ & HR & $95 \% \mathrm{Cl}$ & $P$ & $\%^{\mathrm{b}}$ & HR & $95 \% \mathrm{Cl}$ & $P$ & $\%^{\mathrm{b}}$ \\
\hline Previous schizophrenia & $49(2.9)$ & 1.41 & $0.98-2.04$ & 0.065 & - & - & - & - & - & - & - & - \\
\hline Current schizophrenia & $116(6.8)$ & 1.35 & $1.05-1.73$ & 0.018 & - & - & - & - & 1.26 & $0.98-1.62$ & 0.068 & 22 \\
\hline Previous delusional disorder & $21(1.2)$ & 1.21 & $0.71-2.07$ & 0.477 & - & - & - & - & & - & - & - \\
\hline Current delusional disorder & $29(1.7)$ & 0.92 & $0.55-1.53$ & 0.737 & - & - & - & - & & - & - & - \\
\hline $\begin{array}{l}\text { Previous drug-induced } \\
\text { psychosis }\end{array}$ & $153(8.9)$ & 1.61 & $1.33-1.96$ & $<0.001$ & 1.39 & $1.14-1.70$ & 0.001 & 31 & 1.20 & $0.98-1.47$ & 0.076 & 62 \\
\hline $\begin{array}{l}\text { Current drug-induced } \\
\text { psychosis }\end{array}$ & $50(2.9)$ & 1.50 & $1.07-2.09$ & 0.018 & 1.35 & $0.96-1.90$ & 0.080 & 25 & - & - & - & - \\
\hline \multicolumn{13}{|c|}{$\begin{array}{l}\text { a. Method: Cox regression. Adjusted for age (in years), gender, marital status, ethnicity and socioeconomic status. Also adjusted for comorbid depression. Further adjustment for } \\
\text { violent offending. } \\
\text { b. Percentage change in beta coefficient (beta=log (hazard ratio, HR) from baseline model to final adjusted model. Reported results when \% change in beta coefficient increased } \\
\text { compared with previous step. } \\
\text { Values in bold are significant. }\end{array}$} \\
\hline
\end{tabular}

between current schizophrenia and time to non-violent reoffending was moderately reduced in size and no longer significant. The association between previous drug-induced psychosis and time to non-violent reoffending was moderately altered (31.0\%) following adjustment for treatment for substance dependence. However, following adjustment for drug dependence, this association was considerably reduced in size $(62.0 \%)$ and was no longer significant. The association between current drug-induced psychosis and time to non-violent reoffending was moderately reduced $(25.0 \%)$ following adjustment for treatment for substance dependence and no longer significant.

\section{Sensitivity analysis}

We repeated the above analyses considering schizoaffective disorder as a separate category from schizophrenia. We found no significant associations between schizoaffective disorder and time to offending.

We then repeated the analysis combining schizoaffective disorder, delusional disorder and schizophrenia. The results for drug-induced psychosis remained the same for both violent and non-violent reoffending.

However, despite the current diagnosis of the combined psychosis category mentioned above being associated with time to violent reoffending ( $\mathrm{HR}=1.46,95 \%$ CI $1.08-1.98, P=0.013)$ in the baseline model, when adjusted for treatment with psychotropic medications, the association became non-significant. Treatment with medications explained $21 \%$ of the effect of the diagnosis on time to violence.

Analysis considering associations between current diagnosis of the combined psychoses category and time to non-violent reoffending did not reveal any significant results (baseline $\mathrm{HR}=1.25$, 95\% CI 0.99-1.57, $P=0.057$ ).

\section{Discussion}

\section{Schizophrenia}

We found that prisoners with active symptoms of schizophrenia in the 6 months prior to their release reoffend quicker than prisoners without psychosis. This applied to both violent and nonviolent reoffending. However, for prisoners whose symptoms of schizophrenia had resolved by the time of interview, there were no differences in time to reoffending. These findings confirm that it is essential to consider temporal proximity with active symptoms of schizophrenia when investigating the associations between violence and schizophrenia. ${ }^{1,14,15,20}$ We are not aware of a previous study that has demonstrated this association with shorter time to both violent and non-violent offending.

Treatment with medication in prison delayed reoffending among participants with current symptoms of schizophrenia. The size of the effect was moderate when considering the percentage change of time to subsequent violence. Nevertheless, it is an important finding, and confirmed that services that provide medication to prisoners with schizophrenia continue to exert protective effects on reoffending after release. The moderate level of effect could be explained by participants with poor cooperation with or discontinuation of treatment subsequent to release. This may have led to loss of any beneficial effects achieved while in prison and may have been accompanied by or resulted in additional risk factors including substance misuse following release.

Treatment for substance dependence did not exert additional effects on the association between current schizophrenia and time to violence. This finding was unexpected and suggested that treatment for substance misuse may have not been as important as previously thought in the pathway to violent reoffending among those with active symptoms of schizophrenia. Alternatively, treatment for substance misuse while in prison may have been less effective for this subgroup than for other prisoners (without psychosis).

Consistent with previous research, we found associations between substance dependence and recidivism. ${ }^{5,37,38}$ Comorbid drug dependence was a key factor in the pathway between mental illness and shorter time to both violent and non-violent reoffending. The fact that despite receiving treatments for both mental illness and substance dependence in prison, prisoners with psychosis commit violent offences quicker following release from prison could indicate first, treatment resistant illness, second poor cooperation with treatment and third return to an environment that reinforces non-cooperation with further involvement in criminal activities, particularly when associated with substance misuse. Recent systematic reviews have indicated increased risk of violence among individuals with psychosis compared with the general population but argue that most of the excess risk is mediated by substance misuse comorbidity. ${ }^{2,5}$ In addition to active psychotic symptoms, personality traits and social problems are thought to play an important role in the relationship between substance misuse and violence in schizophrenia. ${ }^{33}$ A representative study of UK prisoners showed that those with psychosis constitute a subgroup with more risk factors for future violence and criminality than prisoners without psychosis, specifically alcohol and drug dependence, together with psychopathy. ${ }^{4}$ 
Because time to violent offending for those with schizophrenia following release is likely to be influenced by a combination of risk factors, including active symptoms of psychosis, substance dependence and personality disorder traits, our findings highlight the need for multiple and complex interventions both in prison and while in the community. These should additionally target the high number of co-occurring conditions if the intention is to delay and reduce violence.

\section{Drug-induced psychosis}

We found that drug-induced psychosis (both previous and current diagnosis) was associated with shorter time to both violent and non-violent reoffending. However, despite presenting with psychotic symptoms, treatment with medication did not modify the effect of drug-induced psychosis on time to future violence. In contrast, treatment for substance dependence had a moderate effect. Whereas it is important to treat distressing symptoms of drug-induced psychosis among prisoners, the main aim of treatment should be to treat the substance dependence if the intention is to delay violence following release.

Our findings additionally suggest that comorbid drug dependence was a key factor in the relationship between previous diagnosis of drug-induced psychosis and subsequent time to nonviolent reoffending. Furthermore, despite receiving treatment for substance dependence in prison, prisoners with both druginduced psychosis and drug dependence committed non-violent offences quicker following release from prison. These findings highlight the need for continuity of treatment and input from relevant services after release because the subgroup of prisoners with drug-induced psychosis represent those with particularly severe and long-standing problems related to drugs, and return to a criminal lifestyle likely to involve both increased risks of violence and return to non-violent, acquisitive recidivism to obtain money for drugs.

\section{Schizophrenia spectrum disorders: sensitivity analysis}

In the sensitivity analysis, we considered schizoaffective disorder separately from schizophrenia. Our findings for schizophrenia remained similar. Schizoaffective disorder was not associated with time to reoffending, a result possibly affected by the small numbers of individuals with schizoaffective disorder.

In a further sensitivity analysis, we considered delusional disorder together with schizophrenia. We found that medication for current symptoms of the psychotic illness had a moderate effect on time to violent reoffending and fully explained the association. Considering all schizophrenia spectrum disorders together increased the sample size; hence the power of the observation, but to the expense of specificity. Our main analysis stipulates that the associations observed were mainly because of the schizophrenia diagnosis, and we therefore presented separately the results for the two diagnoses.

Previous research has suggested that individuals with delusional disorder are both quicker to reoffend violently following discharge from psychiatric services ${ }^{39}$ and have an overall higher risk of reoffending than those with schizophrenia. However, in this sample of released prisoners no associations were found between delusional disorder and either violent or non-violent reoffending. This may be explained by small numbers in our sample with previous and current delusional disorder. Alternatively, that there are differences between individuals with delusional disorder admitted to psychiatric services and those who receive prison sentences.

\section{Limitations}

Psychiatric treatment was broadly defined in this study and primarily self-reported. We did not have robust evidence on cooperation and effectiveness of each treatment while in prison. Furthermore, treatment with medication did not distinguish between different medications and included only oral medication. We did not include medication given via other routes because few prisoners received injectable medication. Similarly, consultations from a mental health professional did not specify the type of therapy received.

Although we considered as time at risk for reoffending time spent outside prison, we did not consider time spent in hospital between release and reconviction in our analysis. This information was not available.

Given the lack of randomisation in our study, our conclusions cannot be drawn without reservation. Furthermore, treatment status was likely to be confounded: prisoners with more severe or overt illness were those who were more likely to be treated. Similarly, those who sought or accepted treatment, and reported having done so, may for other reasons have had lower rates of reoffending. Future research should focus on how prescription and cooperation with specific psychiatric treatments affect time to reoffending.

\section{Implications}

We are not aware of previous research reporting effects of treatment on severe mental illness in prison and subsequent time to reoffending. Our findings highlight the importance of identifying and providing treatment to persons with schizophrenia in prison with medication. It was of concern that nearly a third of prisoners with current symptoms of schizophrenia identified by research interviews did not receive either treatment with medication or consultations with a mental health professional. Similarly, nearly half of those with current delusional disorder did not receive treatment. Because the prisoner cohort study selected prisoners who had committed serious violent and sexual offences, it is probable that they received closer attention from correctional staff and were more likely to be referred for an assessment of their mental health while in the prison setting. A representative survey of prisoners in England and Wales showed that among individuals who screened positive for psychosis, only $47 \%$ of men and $50 \%$ of women received help for mental health problems. ${ }^{40}$ Research has shown that only a quarter of prisoners identified as having severe mental illness were assessed by prison in-reach teams and that only $13 \%$ were accepted onto their case-load for treatment within the first month of incarceration. ${ }^{40}$ Our findings emphasise the importance of improved mental health service provision in prisons, with treatment plans to enhance cooperation following release.

Although we did not find that treatment for substance dependence conveyed a protective effect on prisoners with schizophrenia, and that the beneficial effects were restricted to those with substance dependence, because prisoners with psychotic illness have high levels of comorbidity, particularly substance dependence, such treatment should be routinely considered for inclusion in their treatment plans. For prisoners with druginduced psychosis, treatment for substance dependence appears to increase the protective effect of the treatment for their psychotic symptoms against reoffending.

The findings indicate the importance of improved screening in prisons to ensure those with severe mental illness are identified and receive necessary treatment. Detection of mental illness currently relies on screening on reception into custody. ${ }^{41}$ The focus of research in this area has been on improving screening 
tools for mental disorders for new receptions. ${ }^{42-44}$ However, screening procedures on reception to custody are poor and most cases are missed. ${ }^{41}$ Typically, a large number of prisoners arrive at the same time and main issues such as legal procedures and allocation to residential units within prison are prioritised over detailed mental health assessments. In consequence, screening is a quick procedure, does not take place in a confidential and protected environment, and is therefore not comprehensive. Because researchers were able to identify a substantial proportion of missed cases, screening should be implemented at different stages of incarceration. Furthermore, consideration should be given to improved screening and consideration of treatment plans following release because less than a quarter of prisoners with psychosis will be followed up by a mental health professional on release. $^{24,41}$

Artemis Igoumenou, PhD, Constantinos Kallis, PhD, Professor Jeremy Coid, MD, Violence Prevention Research Unit, Queen Mary University, London, UK

Correspondence: Artemis Igoumenou, Violence Prevention Research Unit, Wolfson Institute of Preventive Medicine, Queen Mary University of London, Garrod Building, Turner Street, London E1 2AD, UK. Email: a.igoumenou@qmul.ac.uk

First received 27 Jan 2015, final revision 7 Aug 2015, accepted 16 Oct 2015

\section{Funding}

This report presents independent research commissioned by the UK National Institute for Health Research (NIHR) under its Program Grants for Applied Research funding scheme (RPPG-0407-10500). The views expressed in this report are those of the authors and not necessarily those of the UK National Health Service, NIHR or the UK Department of Health. The authors had complete freedom to direct the analyses and to report without any influence from the sponsors. There was no editorial direction or censorship from the sponsors.

\section{References}

1 Keers R, Ullrich S, DeStavola BL, Coid JW. Association of violence with emergence of persecutory delusions in untreated schizophrenia. Am J Psychiatry 2014; 171: 332-9.

2 Fazel S, Seewald K. Severe mental illness in 33,588 prisoners worldwide: systematic review and meta-regression analysis. Br J Psychiatry 2012; 200 364-73.

3 Singleton NMH, Gatward R. Psychiatric Morbidity among Prisoners in England and Wales. HMSO, 1998.

4 Coid J, Ullrich S. Prisoners with psychosis in England and Wales: diversion to psychiatric inpatient services? Int J Law Psychiatry 2011; 34: 99-108.

5 Witt K, van Dorn R, Fazel S. Risk factors for violence in psychosis: systematic review and meta-regression analysis of 110 studies. PLoS One 2013; 8: e55942.

6 Baillargeon J, Binswanger IA, Penn JV, Williams BA, Murray OJ. Psychiatric disorders and repeat incarcerations: the revolving prison door. Am J Psychiatry 2009; 166: 103-9.

7 Baillargeon J, Penn JV, Knight $\mathrm{K}$, Harzke AJ, Baillargeon G, Becker EA. Risk of reincarceration among prisoners with co-occurring severe mental illness and substance use disorders. Adm Policy Ment Health 2010; 37: 367-74.

8 Nilsson T, Wallinius M, Gustavson C, Anckarsater $\mathrm{H}$, Kerekes N. Violent recidivism: a long-time follow-up study of mentally disordered offenders. PLOS One 2011; 6 : 25768

9 Hall DL, Miraglia RP, Lee LW, Chard-Wierschem D, Sawyer D. Predictors of genera and violent recidivism among SMI prisoners returning to communities in New York State. J Am Acad Psychiatry Law 2012; 40: 221-31.

10 Bonta J, Law $\mathrm{M}$, Hanson $\mathrm{K}$. The prediction of criminal and violent recidivism among mentally disordered offenders: a meta-analysis. Psychol Bull 1998; 123 $123-42$.

11 O'Driscoll C, Larney S, Indig D, Basson J. The impact of personality disorders, substance use and other mental illness on re-offending. J Forensic Psychiatry Psychol 2012; 23: 382-91.

12 Grann M, Danesh J, Fazel S. The association between psychiatric diagnosis and violent re-offending in adult offenders in the community. BMC Psychiatry 2008; 25: 8
13 Walter M, Wiesbeck GA, Dittmann V, Graf M. Criminal recidivism in offenders with personality disorders and substance use disorders over 8 years of time at risk. Psychiatry Res 2011; 186: 443-5.

14 Van Dorn R, Volavka J, Johnson N. Mental disorder and violence: is there a relationship beyond substance use? SOc Psychiatry Psychiatr Epidemiol 2012; 47 487-503.

15 Odgers CL, Mulvey EP, Skeem JL, Gardner W, Lidz CW, Schubert C. Capturing the ebb and flow of psychiatric symptoms with dynamical systems models. Am J Psychiatry 2009; 166: 575-82.

16 Coid JW, Ullrich S, Kallis C, Keers R, Barker D, Cowden F, et al. The relationship between delusions and violence findings from the East London first episode psychosis study. JAMA Psychiatry 2013; 70: 465-71.

17 Ullrich S, Keers R, Coid JW. Delusions, anger, and serious violence: new findings from the MacArthur Violence Risk Assessment Study. Schizophr Bull 2014; 40 $1174-81$.

18 Keers R. Community treatment for violence in released inmates with schizophrenia response. Am J Psychiatry 2014; 171: 797.

19 Lichtenstein P, Halldner L, Zetterqvist J, Sjolander A, Serlachius E, Fazel S, et al. Medication for attention-deficit disorder and criminality. N Engl J Med 2012; 367 2006-14.

20 Swanson JW, Swartz MS, Elbogen EB. Effectiveness of atypical antipsychotic medications in reducing violent behavior among persons with schizophrenia in community-based treatment. Schizophr Bull 2004; 30: 3-20.

21 Swanson JW, Swartz MS, Van Dorn RA, Volavka J, Monahan J, Stroup TS, et a Comparison of antipsychotic medication effects on reducing violence in people with schizophrenia. Br J Psychiatry 2008; 193: 37-43.

22 Baillargeon J, Hoge SK, Penn JV. Addressing the challenge of community reentry among released inmates with serious mental illness. Am J Community Psychol 2010; 46: 361-75

23 Lennox C, Senior J, King C, Hassan L, Clayton R, Thornicroft G, et al. The management of released prisoners with severe and enduring mental illness. J Forensic Psychiatry Psychol 2012; 23: 67-75.

24 Melzer DT, Tom BDM, Brugha T, Fryers T, Grounds A, Johnson T, et al. Prisoners with psychosis in England and Wales: a one-year national follow-up study. Howard J Criminal Justice 2002; 41: 1-13.

25 Coid J, Yang M, Ullrich S, Zhang TQ, Sizmur S, Roberts C, et al. Gender differences in structured risk assessment: comparing the accuracy of five instruments. J Consult Clin Psychol 2009; 77: 337-48.

26 Copas J, Marshall P. The offender group reconviction scale: a statistical reconviction score for use by probation officers. J Roy Stat SoC C 1998; $\mathbf{4 7}$ 159-71.

27 Endicott J, Spitzer RL. A diagnostic interview: the schedule for affective disorders and schizophrenia. Arch Gen Psychiatry 1978; 35: 837-44.

28 Cotton SM, Lambert M, Schimmelmann BG, MacKinnon A, Gleeson JFM, Berk M, et al. Differences between first episode schizophrenia and schizoaffective disorder. Schizophr Res 2013; 147: 169-174.

29 Carli V, Mandelli L, Postuvan V, Roy A, Bevilacqua L, Cesaro C, et al. Self-harm in prisoners. CNS Spectr 2011; 16: 75-81.

30 Paparelli A, Di Forti M, Morrison PD, Murray RM. Drug-induced psychosis: how to avoid star gazing in schizophrenia research by looking at more obvious sources of light. Front Behav Neurosci 2011; 5: 1

31 Babor TF, Higgings-Briddle JC, Saunders JB, Monteiro M. The Alcohol Use Disorders Identification Test. 2nd edn. World Health Organization, 2001.

32 First MB, Gibbon M, Spitzer RL, Williams JBW, Benjamin LS. Structured Clinical Interview for DSM-IV Axis II Personality Disorders, (SCID-II). American Psychiatric Press, 1997

33 Fazel S, Yu R. Psychotic disorders and repeat offending: systematic review and meta-analysis. Schizophr Bull 2011; 37: 800-10.

34 Coid J, Freestone M, Ullrich S. Subtypes of psychopathy in the British household population: findings from the national household survey of psychiatric morbidity. Soc Psychiatry Psychiatr Epidemiol 2012; 47: 879-91.

35 Becker MA, Andel R, Boaz T, Constantine R. Gender differences and risk of arrest among offenders with serious mental illness. J Behav Health Serv Res 2011; 38 $16-28$.

36 Hakansson A, Berglund $M$. Risk factors for criminal recidivism - a prospective follow-up study in prisoners with substance abuse. BMC Psychiatry 2012; 12: 111

37 Swanson JW, Borum, R, Swartz, MS, Monahan, J. Psychotic symptoms and disorders and the risk of violent behaviour in the community. Criminal Behav Ment Health 1996; 6: 309-29.

38 Wilson AB, Draine J, Hadley $T$, Metraux S, Evans A. Examining the impact of mental illness and substance use on recidivism in a county jail. Int I Law Psychiatry 2011; 34: 264-8. 
39 Coid J, Yang M, Ullrich S, Hickey N, Kahtan N, Freestone M. Psychiatric diagnosis and differential risks of offending following discharge. Int J Law Psychiatry 2015; 38: 68-74.

40 HM Prison Service, NHS Executive. The Future Organisation of Prison Health Care. HM Prison Service \& NHS Executive, 1999. Avaialable at: (http://webarchive. nationalarchives.gov.uk/+/uww.dh.gov.uk/en/publicationsandstatistics/publications/ publicationspolicyandguidance/dh_4006944).

41 Senior J, Birmingham L, Harty MA, Hassan L, Hayes AJ, Kendall $K$, et al. Identification and management of prisoners with severe psychiatric illness by specialist mental health services. Psychol Med 2013; 43: 1511-20.
42 Evans C, Brinded P, Simpson Al, Frampton C, Mulder RT. Validation of brief screening tools for mental disorders among New Zealand prisoners. Psychiatr Serv 2010; 61: 923-8.

43 Martin MS, Wamboldt AD, O'Connor SL, Fortier J, Simpson Al. A comparison of scoring models for computerised mental health screening for federal prison inmates. Crim Behav Ment Health 2013; 23: 6-17.

44 Mclnerney C, Davoren M, Flynn G, Mullins D, Fitzpatrick M, Caddow M, et al. Implementing a court diversion and liaison scheme in a remand prison by systematic screening of new receptions: a 6 year participatory action research study of 20,084 consecutive male remands. Int J Ment Health Syst 2013; 7: 18. 